\title{
The role of big data in smart city
}

${ }^{1}$ Ibrahim Abaker Targio Hashem, ${ }^{2}$ Victor Chang , ${ }^{1}$ Nor Badrul Anuar, ${ }^{1}$ Kayode Adewole, ${ }^{1}$ Ibrar Yaqoob, ${ }^{1}$ Abdullah Gani, ${ }^{1}$ Ejaz Ahmed, ${ }^{1}$ Haruna Chiroma

targio@siswa.um.edu.my, ic.victor.chang@gmail.com, badrul@um.edu.my, adewole.ks@gmail.com, ibraryaqoob@siswa.um.edu.my, abdullah@um.edu.my,imejaz@siswa.um.edu.my, freedonchi@yahoo.com

${ }^{1}$ Centre for Mobile Cloud Computing Research, Faculty of Computer Science and Information Technology, University of Malaya, 50603 Lembah Pantai, Kuala Lumpur, Malaysia

${ }^{2}$ Xi'an Jiaotong Liverpool University, Suzhou, China

\begin{abstract}
The expansion of big data and the evolution of Internet of Things (IoT) technologies have played an important role in the feasibility of smart city initiatives. Big data offer the potential for cities to obtain valuable insights from a large amount of data collected through various sources, and the IoT allows the integration of sensors, radiofrequency identification, and Bluetooth in the real-world environment using highly networked services. The combination of the IoT and big data is an unexplored research area that has brought new and interesting challenges for achieving the goal of future smart cities. These new challenges focus primarily on problems related to business and technology that enable cities to actualize the vision, principles, and requirements of the applications of smart cities by realizing the main smart environment characteristics. In this paper, we describe the existing communication technologies and smart-based applications used within the context of smart cities. The visions of big data analytics to support smart cities are discussed by focusing on how big data can fundamentally change urban populations at different levels. Moreover, a future business model that can manage big data for smart cities is proposed, and the business and technological research challenges are identified. This study can serve as a benchmark for researchers and industries for the future progress and development of smart cities in the context of big data.
\end{abstract}

Keywords: Smart City, Big data, Internet of Things, Smart environments, Cloud computing

\subsection{Introduction}

The paradigm shift from the realm of traditional desktop computing to an increasingly sophisticated computing (Gubbi et al., 2013) as well as the significant increase in connected devices and sensors have made feasible the vision for living in a smart environment. Several applications of a smart environment have been introduced recently, including smart homes (Caragliu et al., 2011), smart grids (S.-y. Chen et al., 2009), smart transportation (Adeli \& Jiang, 2009), smart healthcare (Demirkan, 2013), and smart cities (Caragliu et al., 2011; Chourabi et al., 2012), because of the growth of urban population and rapid urbanization. At present, urban performance depends not only on the physical infrastructure but also on the availability and quality of knowledge communication and social 
infrastructure (Caragliu et al., 2011). The key enabler of these smart city applications is possibly the IoT in which everyday objects and devices are connected to the network technologies.

The promise of a smart city leads to an exponential increase in data by several orders of magnitude. Consequently, such enormous volumes of data or big data are at the core of the services rendered by the IoT. The phenomenon of big data has long been characterized by volume, velocity, and a variety of data types that have been created at everincreasing rates (Khan et al., 2014). Big data offers the potential for the city to obtain valuable insights from a considerable amount of data collected through various sources. Certainly, the characteristics of such data mostly include unstructured features compared with big data collected by other means (M. Chen et al., 2014). Figure 1 illustrates the landscape of the smart technologies with big data and cloud computing, in which various smart applications exchange information using embedded sensor devices and other devices integrated with the cloudcomputing infrastructure to generate large amounts of unstructured data. These large amounts of unstructured data are collected and stored in the cloud or data center using distributed fault tolerant databases such as Not Only SQL, which is used to improve a single service or application and is shared among various services (Borgia, 2014). Thus, the programming model for processing large data sets with parallel algorithms can be used for data analytics to obtain value from the stored data.

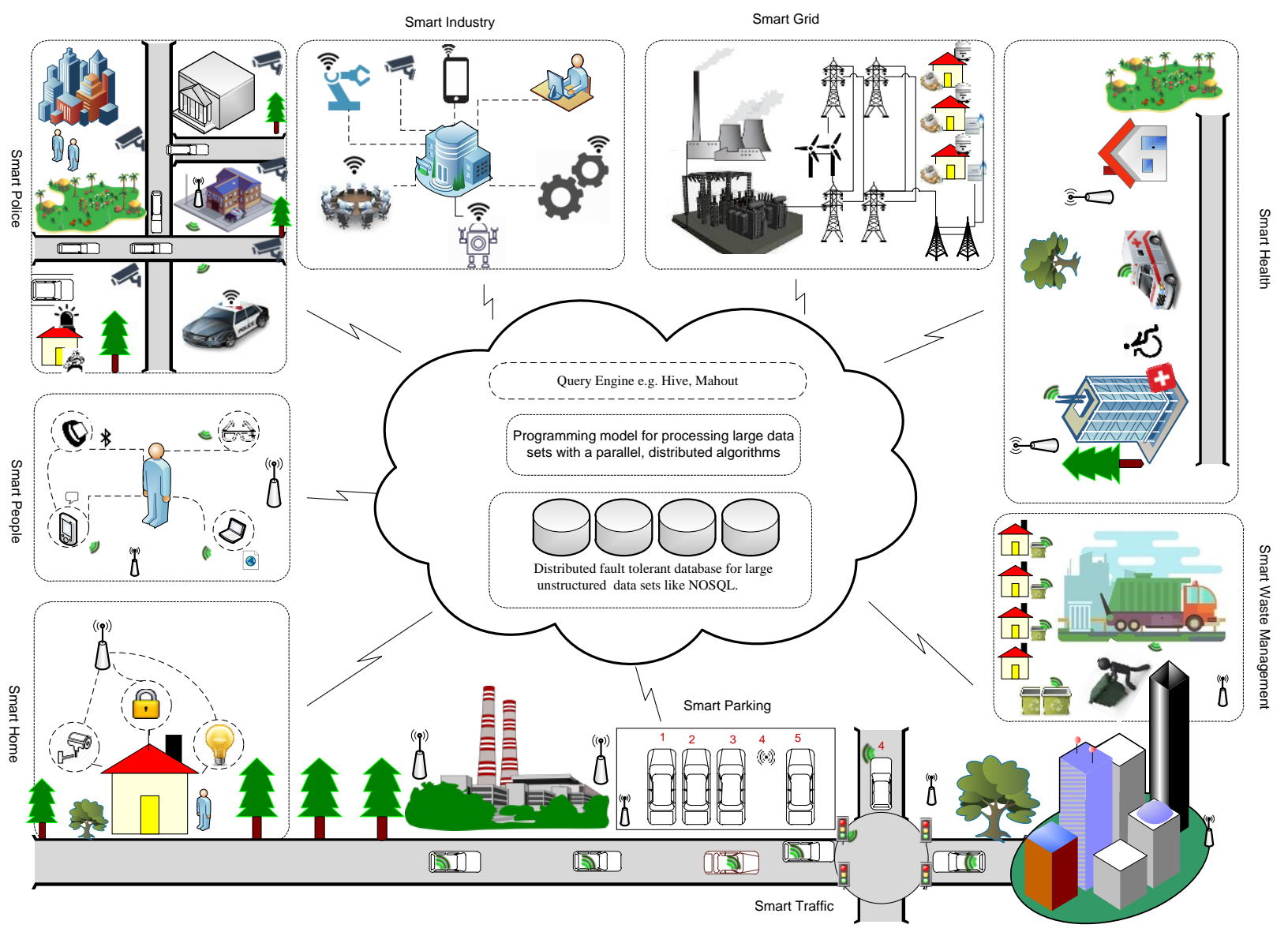


Fig. 1 Landscape of the smart city and big data technologies

Smart cities have played a key role in transforming different areas of human life, touching sectors such as transportation, health, energy, and education. For example, the data of weather information are significantly increasing at a rapid pace. Identifying and obtaining valuable information from large amounts of weather data can be extremely beneficial in terms of agricultural development. Moreover, analytics of the weather data can help inform the people in advance about the possible hazardous conditions (e.g., flood information, extremely hot weather, drought, and so on) (Fan \& Bifet, 2013). Governments have begun to embrace smart city ideas to improve the living standard of their citizens and to implement big data applications (Jimenez et al., 2014). Big data for the smart city can transform every sector of a nation's economy (Batty, 2013). Such transformation enables cities to actualize the learning principles and requirements of the applications of the smart city by realizing the main smart environment characteristics. These characteristics include, among other things, sustainability, resilience, governance, improved quality of life, and intelligent management of natural resources and city facilities (Al Nuaimi et al., 2015). The smart city takes advantage of emerging technologies, such as wireless sensor networks (WSN), to reduce cost and resource consumption. However, applying big data analytics in the smart environment remains in its infancy stage. One of the emerging technologies with the huge potential to enhance smart city services is big data analytics (Al Nuaimi et al., 2015). At present, a large amount of data is being generated from different data sources, such as smartphones, computers, sensors, cameras, global positioning systems, social networking sites, commercial transactions, and games. Given that the data generated in our present digitized world continuously grow, efficient data storage and processing facilities have posed challenges to the traditional data mining and analytics platforms. Big data analytics can extract meaningful information from the oceans of data produced by sensor devices. Effective analysis and utilization of big data is a key factor for the success in many business and service domains, including the smart city application. The application of big data in a smart city has many benefits and challenges, including the availability of large computational and storage facilities to process streams of data produced within a smart city environment. One of the possible means to tap this benefit is a reliance on cloud computing services and IoT technologies.

The goal of this study is to offer a comprehensive survey of big data in smart cities, more specifically, the role of big data for sustainability and improvement on the living standards in urban cities. Thus, this paper is motivated by two factors. First is the current availability of smart devices that generate large heterogeneous datasets every day. The second factor is the smart applications that offer a seamless connection between different objects involved in smart city realization. Possibly, the most relevant related work appears in (Al Nuaimi et al., 2015; Kitchin, 2014). However, our study differs from the previous papers by providing a comprehensive and in-depth analysis of state-ofthe-art technologies and by presenting a structure of big data in smart cities. Other related work includes big data, smart cities, and city planning (Batty, 2013) and intelligent services for big data science (Dobre \& Xhafa, 2014). The work in (Gubbi et al., 2013) offers a conceptual IoT framework with cloud computing at the center as well as a model of end-to-end interaction between various stakeholders in a cloud-centric IoT framework, thereby making the model comparable to the structure of big data in a smart city. 
The rest of the paper is organized as follows. Section 2 discusses state-of-the-art smart cities and big data. Section 3 presents the smart city technologies. Section 4 proposes a new structure of big data and smart city. Section 5 provides smart-based applications, which include healthcare, transportation, governance, and smart grid. Section 6 proposes a future business model. Section 7 looks at the different case studies of a smart city. Section 8 discusses the research challenges that remain to be addressed as future research directions. Section 9 provides the concluding remarks.

\subsection{State-of-the-Art Technologies}

The IoT provides a platform for sensors and actuator devices to communicate seamlessly within the smart city environment and enables an increasingly convenient information sharing across platforms (Gubbi et al., 2013). The recent adaptation of different wireless technologies places IoT as the next revolutionary technology by benefiting from the full opportunities offered by the Internet technology. The IoT has witnessed recent implementation in the smart city to develop intelligent systems such as smart grids, smart retail, smart homes, smart water, smart transportation, smart healthcare, and smart energy (Gubbi et al., 2013). However, a universally agreed definition of a smart city is yet to be conceived, and recognizing common global trends is challenging (Morabito, 2015). The smart city focuses on applying the next-generation information technology to all walks of life, embedding sensors and equipment in hospitals, power grids, railways, bridges, tunnels, roads, buildings, water systems, dams, oil and gas pipelines as well as other objects worldwide, thereby forming the IoT ( $\mathrm{Su}, \mathrm{Li}$, Fu, et al., 2011). The Internet revolution led to the interconnection between people at an unprecedented scale and pace. The next revolution will be the interconnection between objects to create a smart city. The smart city emphasizes the interconnection of sensing and actuating devices, thereby allowing information sharing across platforms through a unified framework. Such sharing is achieved by seamless ubiquitous sensing, data analytics, and information representation with cloud computing as the unifying framework. The present is the post-PC era, in which smartphones and other handheld devices are changing our environment by making it increasingly interactive and informative (Gubbi et al., 2013).

Big data systems are stored, processed, and mined in smart cities efficiently to produce information to enhance different smart city services. In addition, big data can help decision makers plan for any expansion in smart city services, resources, or areas. The various characteristics of big data demonstrate its considerable potential for gains and advancements. The possibilities are endless; however, they are bounded by the availability of advanced technologies and tools. Big data can achieve its goals and can advance the services in smart cities using the right tools and methods for efficient and effective data analysis. Such effectiveness will encourage collaboration and communication between entities and can facilitate the creation of additional services and applications that can further enhance the smart city. The big data applications can serve many sectors in a smart city, thereby providing better customer experiences and services, which help businesses achieve improved performance (e.g., higher profits or increased market shares). Healthcare can be enhanced by improving preventive care services, diagnosis and treatment tools, healthcare records management, and patient care. Transportation systems can greatly benefit from big data to optimize routes and schedules, accommodate varying demands, and increase environmental friendliness. 
Cloud computing (Mell \& Grance, 2011) is used to describe a variety of different types of computing models that involve many computers or clusters connected through a real-time communication network. Cloud computing provides services to perform complex large-scale computing tasks such as mining big social network data generated through smartphone applications (V. Chang et al., 2010). Cloud computing services, such as platform as a service (PaaS), software as a service, and infrastructure as a service, can be combined with IoT. Such an amalgamation can transform every business; with the introduction of big data technology, a large amount of data can be processed easily. Moreover, cloud computing can provide the virtual infrastructure for utility computing that integrates monitoring devices, storage devices, analytics tools, visualization platforms, and client delivery (Armbrust et al., 2010). The cost-based model that uses a business framework that cloud computing can offer will enable end-to-end service provisioning for businesses and users to access applications on demand from anywhere (Victor Chang et al., 2010; Chang et al., 2013). Cloud computing also provides the underlying engine via the big data technology such as Hadoop framework (Hashem et al., 2015). Hadoop was introduced to provide an enabling platform and programming models for the distributed processing of large datasets across different clusters. Hadoop comprises two primary components: Hadoop Distributed File System and MapReduce, which are closely related to each other (Hashem et al., 2016; Hashem et al., 2015). Although the real-time requirements of data storage and processing in the smart city are considered, the adoption of streaming architecture will guarantee the efficient and seamless communication between sensing devices within the smart city network. Such technology has been adopted recently with the introduction of many stream processing platforms, such as Apache S4, Storm, and Spark streaming, which can enable data storage and processing across various interconnected nodes.

\subsection{Emerging Communication Technologies}

Most big data applications for smart cities require smart networks that connect their components, including the residents' equipment such as cars, smart house devices, and smartphones. This network should be capable of efficiently transferring the collected data from their sources to where big data is collected, stored, and processed and to transfer responses back to the different entities that need them in the smart city ( $\mathrm{Al} \mathrm{Ni}$ ). The quality of service (QoS) support in the network is extremely important for real-time big data applications for smart cities. In these applications, all current distributed application events should be transferred in real-time to where they can be processed. These events can be transferred from their sources as raw events or as filtered or aggregated events. In this section, we highlight the different technologies from which the smart city environment can benefit, including smart city IoT and big data technologies. For the smart city to be embraced, the IoT technology that allows different objects to be sensed and controlled remotely across existing network infrastructure needs to be implemented. This undertaking will create opportunities for achieving flexible integration of the various objects in the smart city. Such innovation will improve efficiency and accuracy, as well as provide economic benefits when IoT is augmented with sensors and actuator components. As previously emphasized, an open standard IoT technology will be optimal to achieve this goal. Organizations such as the XMPP initiative, via its XSF foundation, create a framework for open standard technology that is neither tied to any company nor connected with any cloud services. Technology such as REST provides scalable architecture, which allows objects to communicate over Hypertext Transfer Protocol and is 
easily adopted for IoT applications to provide communication from any object to a central web server (Atzori et al., 2010).

\subsection{RFID}

RFID operates based on electromagnetic fields to automatically identify and track tags attached to objects. The tags contain electronically stored information and can be active, passive, or battery-assisted passive types. The active type is battery-powered and transmits its ID signal periodically. The passive types are not battery-powered; they use the radio energy transmitted by the reader. The battery-assisted passive type has a small on-board battery and transmits only in the presence of RFID reader. The RFID technology represents a breakthrough in embedded communication and can be used to identify virtually any object, including animals, clothes, and even human beings. This robust application of RFID has made the technology suitable for smart cities; RFID can be applied in hospitals, libraries, and for monitoring cargo (Juels, 2006). Unlike a barcode, an RFID tag can be put inside any object and the reader can still read the signal even when the tag is invisible. This capability has placed RFID at the forefront of building embedded devices with full tracking functionality. For instance, RFID tags can be embedded in a meter, thereby making it a smart reading device. RFID tags are used in many organizations. For example, an RFID tag attached to an automobile during production can be used to track its progress through the assembly line. The RFID microchips embedded in livestock and pets allow the positive identification of animals (Angell \& Kietzmann, 2006). Such an identification method enables the realization of smart city intelligent devices through the RFID embedded technology.

\subsection{WSN}

WSN is a network of distributed autonomous sensing nodes that use low-power integrated circuits and wireless communication technology to distribute data among the connected sensor devices. This network supports hundreds to thousands of low-cost and low-power miniature devices that are connected to one or more sensors. The sensor has a radio transceiver to send and receive signals, as well as a microcontroller, which is an electronic circuit to interface with the sensors and an energy source, usually a battery or an embedded form of energy harvesting (Dargie \& Poellabauer, 2010). The ability of the WSN to connect devices with low cost and sizes has improved the possibility of using a sensor network with numerous intelligent sensors. This network enables the seamless connection and sharing of valuable information from different environments, which can be processed and analyzed efficiently (Al Nuaimi et al., 2015). This characteristic of WSN enables it to be useful in many areas, such as industrial process monitoring and control, machine health monitoring, natural disaster prevention, as well as water quality monitoring. The WSN can cope with large-scale deployment in any environment, and it is therefore applicable for smart city integration. The network provides a simple economic approach for deploying distributed monitor and control devices, thereby avoiding the overhead cost that may be incurred in wired systems. The WSN can monitor physical and environmental conditions in real time, such as temperature, pressure, light, and humidity. The devices, such as switches, motors, or actuators, control these environmental conditions via an efficient wireless communication. These characteristics enable WSN to be applicable for smart homes, smart buildings, and for smart health. Although 
WSN faces the challenges of energy consumption most especially at the application level, a number of protocols have been studied to improve WSN in this area (Patil \& Biradar, 2012). The wide adoption of WSN can improve communication and businesses in a smart environment. For instance, a WSN project that uses bus infrastructure has been adopted in India and Cambodia to provide villagers with the access to Internet services (Oualhaj et al., 2015).

\subsection{WiFi, Ultra-Wideband, ZigBee, and Bluetooth}

A city can be considered smart if it has integrated wireless communication platforms. Wireless communication is a fast-growing technology that provides increasing flexibility and mobility. Wireless technology offers dynamic network formation, low cost, and easy deployment. WiFi is a wireless protocol that serves as a replacement for the standard cable networks and allows users to access the Internet at broadband speeds when connected to an access point or when in ad-hoc mode. Ultra-wideband is oriented to high-bandwidth indoor short-range wireless networks over multimedia links. ZigBee is also designed for short-range wireless communication with provision for long lifetime battery usage capability. Bluetooth is a standard based on a wireless radio system designed for short-range and cheap devices to replace cables for computer peripherals, such as mice, keyboards, joysticks, and printers (Lee et al., 2007). These short-range wireless technologies have played a key role in wireless data transmission, providing low-power consumption network. However, given that some smart devices have great tendency to move from one network to another without communication challenges, the QoS provided by wireless communication technology needs to be improved. The reliability of the wireless communication networks is of utmost importance in smart city realization, coupled with the need for self-organizing and self-healing networks.

\subsection{G LTE, LTE-A, and 5G}

The LTE technology is used to describe 4G wireless network, which is an extension of the existing 3G wireless standards. As such an extension, $4 \mathrm{G}$ shifts the paradigm from hybrid data and voice networks to a data-only IP network. Furthermore, $4 \mathrm{G}$ uses multiple-input multiple-output (MIMO) and orthogonal frequency division multiplex (OFDM) to acquire more data throughput than 3G. OFDM is a transmission technique that uses many closely spaced carriers modulated with low data rates. This technique is a spectral efficiency scheme that enables high data rates and permits multiple users to share a common channel. To further improve data throughput and spectral efficiency, MIMO uses multiple antennas at the transmitter and receiver. The $4 \mathrm{G}$ wireless networks are expected to be used for the majority of the machine for machine communication traffic (Abdalla \& Venkatesan, 2012). LTE-Advanced (LTE-A) bridges the gap between $4 \mathrm{G}$ and $5 \mathrm{G}$ by introducing high bandwidths, and it promises nearly three times greater speed than does the basic LTE network and comprises carrier aggregation, increased MIMO, coordinated multipoint, relay station, and heterogeneous network. In addition, 5G is an improved technology that provides a platform for collecting more than one hundred billion devices and supports bandwidth of up to $10 \mathrm{Gbit} / \mathrm{sec}$ with a relatively low latency. Such technology remains in its infancy and is currently undergoing a series of pilot projects. The widespread deployment of 5G networks is projected for 2020 (Ahmad, 2015). The introduction of 5G networks will result in fast and resilient access to the Internet and support for smart city realization. Such networks will introduce new architectures, such as cloud RAN and virtual RAN, which can facilitate an increasingly centralized network establishment and make the best use of server farms through localized data centers at the network edges. 


\subsection{Network Function Virtualization}

The problem of managing network infrastructure has been a concern among network service providers. This problem does not only affect revenue but also limits innovation in the telecommunication industry. Thus, network operators seek to minimize or eliminate their dependence on proprietary hardware (Hawilo et al., 2014). The need to shift the paradigm from a reliance on hardware for core network function gave rise to network function virtualization (NFV). The group of seven telecom operators from the European Telecommunications Standards Institute formed industrial specifications for NFV. NFV is a technology introduced to take advantage of the evolution of information technology virtualization. This technology transfers hardware-based network functions to software-based applications running on commercial off-the-shelf equipment. With the use of NFV, network functions can be initiated from different locations such as data centers, network nodes, and end-user (Operators Network, 2012). This emerging technology provides many benefits, including platform openness, scalability, flexibility, performance improvement, reduced capital, and operating expenditures. The NFV provides support for the following components: physical server, hypervisor, and guest virtual machine. The physical server provides physical resources such as CPU, storage, and RAM. The hypervisor is a virtual machine monitor, which manages physical resources and provides the environment for guest virtual machine to execute. By contrast, the guest virtual machine is a software that emulates the architecture and functionalities of a physical platform on which the desired application is executed. The NFV technology takes advantage of cloud-based infrastructure and networking services to form the NFV infrastructure (Hawilo et al., 2014). Therefore, the applications of this technology to the smart city will include the virtualization of mobile base stations, PaaS, content delivery networks, and home environments.

\subsection{Applications of Big Data in the Smart City}

The application of big data technologies for the smart city enables efficient data storage and processing to produce information that can enhance different smart city services. In addition, big data helps decision makers plan for any expansion in smart city services and resources. For big data to achieve its goals and advance services in smart cities, it needs the right tools and methods for efficient and effective data analysis. These tools and methods may encourage collaboration and communication between entities and provide services to many sectors in the smart city, as well as improve customers' experiences and business opportunities. Table 1 provides a summary of the different smart city applications.

\subsection{Smart Grid}

The rapid distribution of smart grids has enabled researchers to integrate, analyze, and use real-time power generation and consumption data, as well as other types of environmental data. The improvement in energy efficiency and intelligent services is expected to result in a high investment efficiency of the existing smart grid infrastructure. In a smart grid environment, a large amount of data is generated from different sources, such as the power utilization habits of users, phasor measurement data for situational awareness, and energy consumption data measured by widespread smart meters, among others (Lai \& McCulloch, 2015). The efficient use of big data collected from the smart grid environment can help decision makers come up with a wise decision in terms of the 
supply level of electricity while fulfilling the demands of the user. The analytics of the smart grid data can also help predict the need of the power supply in the future. Furthermore, the analytics of smart grid data can help meet the strategic objectives through specific pricing plans consistent with the supplies, demand, and production models (Al Nuaimi et al., 2015).

\subsection{Smart Healthcare}

In the past decade, an enormous amount of data has been generated in the healthcare sector (Demirkan, 2013). The rapid rate of increase in the world's population has facilitated the rapid changes in the models of treatment delivery, and many decisions behind those changes are driven by data. Proper analytics tools can allow healthcare specialists to collect and analyze patients' data, which can likewise be used by insurance agencies and administration organizations. Moreover, proper analytics of big healthcare data can help predict epidemics, cures, and diseases, as well as improve quality of life and avoid preventable death. The sum and constant nature of information accumulated for specific patients' health issues can be increased via intelligent gadgets, which are associated with the home or clinics to monitor behaviors to help understand patient records. In addition, the analytics of large amounts of healthcare data can enable doctors to detect the warning signs of serious illness during the early stage of treatment, which can save hundreds of lives (Roy et al., 2007).

\subsection{Smart Transportation}

The patterns obtained from the large amounts of traffic data can help improve transportation systems in terms of minimizing traffic congestion by providing alternative routes and reducing the number of accidents by analyzing the history of mishaps, including factors such as their cause and the driver speed. The data generated by transport systems can also help optimize freight movements (Ju et al., 2013). Moreover, the big data collected from smart transport systems can help consolidate shipments and optimize shipping movements by reducing supply chain wastage. Smart transport data can also provide many benefits, such as reducing the environmental impact and increase safety as well as improving end-to-end user experience, among many others.

\subsection{Smart Governance}

Big data analytics can play an important role in enabling smart governance (Meijer \& Bolívar, 2015; Willke, 2007). The organization or agencies with common interests can easily be identified via data analysis that can lead toward collaboration among them. This collaboration can lead countries toward development. Moreover, big data analytics can help governments establish and implement satisfactory policies because they are already familiar with the needs of the people in terms of health, social care, education, and so on. In addition, the ratio of unemployment can also be reduced by analyzing the big data of different educational institutes.

\begin{tabular}{|l|l|l|l|l|l|}
\hline Application & Specific Use & IoT & $\begin{array}{l}\text { Possible } \\
\text { Communication } \\
\text { Technologies }\end{array}$ & Advantages & Limitations \\
\hline Smart & Health monitoring, & Sensors, $\quad$ smart & Bluetooth ZigBee & - Early diagnose the & - Lack of precision \\
\hline
\end{tabular}




\begin{tabular}{|c|c|c|c|c|c|}
\hline Healthcare & & wearable devices & & disease & \\
\hline $\begin{array}{l}\text { Smart } \\
\text { Transportation }\end{array}$ & $\begin{array}{ll}\text { Efficient } & \text { route } \\
\text { management } & \end{array}$ & $\begin{array}{ll}\text { Smart } & \text { Cars, } \\
\text { Cameras, } & \text { RFID } \\
\text { cards } & \end{array}$ & RFID, 3G, and 4G & $\begin{array}{ll}- & \text { Automatic traffic } \\
\text { management } \\
\text { - } & \text { Efficient route } \\
\text { management } \\
\text { - Less congestion }\end{array}$ & $\begin{array}{l}\text { Network } \\
\text { disconnectivity } \\
\text { can cause serious } \\
\text { accidents }\end{array}$ \\
\hline $\begin{array}{l}\text { Smart } \\
\text { Governance }\end{array}$ & $\begin{array}{l}\text { To make smart } \\
\text { policies with the aim } \\
\text { of managing the } \\
\text { citizens }\end{array}$ & $\begin{array}{l}\text { Smartphones, } \\
\text { cameras, sensors }\end{array}$ & $\begin{array}{l}\text { WiFi, LTE, LTE-A, } \\
\text { WiMax, Bluetooth, } \\
\text { LoRaWAN, }\end{array}$ & $\begin{array}{l}\text { Awareness in } \\
\text { terms of citizens } \\
\text { needs } \\
\text { Clear policy }\end{array}$ & $\begin{array}{l}\text { Collection and } \\
\text { analysis of data } \\
\text { seem difficult } \\
\text { task }\end{array}$ \\
\hline Smart Grid & $\begin{array}{l}\text { To manage the power } \\
\text { supply }\end{array}$ & $\begin{array}{l}\text { Smart meters and } \\
\text { Smart readers }\end{array}$ & WiFi, Zigbee, Z-Wave & $\begin{array}{ll}\text {-Efficient } & \text { power } \\
\text { supply } & \\
-\quad \text { Future } & \text { needs } \\
\text { estimation } & \end{array}$ & $\begin{array}{l}\text { - Costly } \\
\text { - Hard to manage }\end{array}$ \\
\hline
\end{tabular}

Table 1. Summary of different smart city applications

\subsection{Proposed Structure of the Big Data and Smart City}

With smart city applications producing continuous large data from heterogeneous sources, existing relational database technologies are inadequate to handle such huge amounts of data given the limited processing speed and the significant storage expansion cost. To address this problem, big data processing technologies, which are based on distributed data management and parallel processing, have provided enabling platforms for data repositories, distributed processing, and interactive data visualization (Kang et al., 2016).

The system structure of big data in the smart city, as shown in Figure 2, can be divided into multiple layers to enable the development of integrated big data management and smart city technologies. Each layer represents the potential functionality of big data smart city components. The first layer is the set of objects and devices connected via local and/or wide-area networks. Most of these objects and devices actively generate a huge amount of unstructured data every second. In the second layer, all the collected unstructured data are stored in a shared distributed fault-tolerant databases located either in the city data center equipped with all network elements or by big data storage such as S3, Google cloud services, and Azure from vendors such as Amazon, Google, Microsoft, and Cloudera. Various big data store systems can be used in these cases such as Cassandra, Hbase (George, 2011), MangDB, CouchDB, Voldemort, DynamoDB, and Redis. Within the same layer, the stored data are processed depending on the incoming queries using batch based programming model such as MapReduce framework (Dean \& Ghemawat, 2008) or other processing engines used for big data. MapReduce provides a powerful programming model for parallel and distributed processing of large data on clusters. In stream processing, data must be processed quickly so that companies and individuals can react to changes in real time in a smart city environment. Many technologies can help process and act on real-time streaming unstructured data in real time such as Spark, Storm, and S4 (Neumeyer et al., 2010). The smart analysis shown in Figure 1 can be designed using scalable machine learning algorithms or other novel data mining algorithms to provide extraction of patterns and knowledge from large amounts of data. A typical 
example of such technology is Apache Mahout (Owen et al., 2011), in which many machine learning libraries for data filtering, clustering, and classification can be found. The last layer is the application services, in which people and machines directly interact with each other to make smart decisions. Such applications can be used for different purposes such as recommendation, fraud detection, sentiment analysis, intelligent traffic management, and web display analysis.

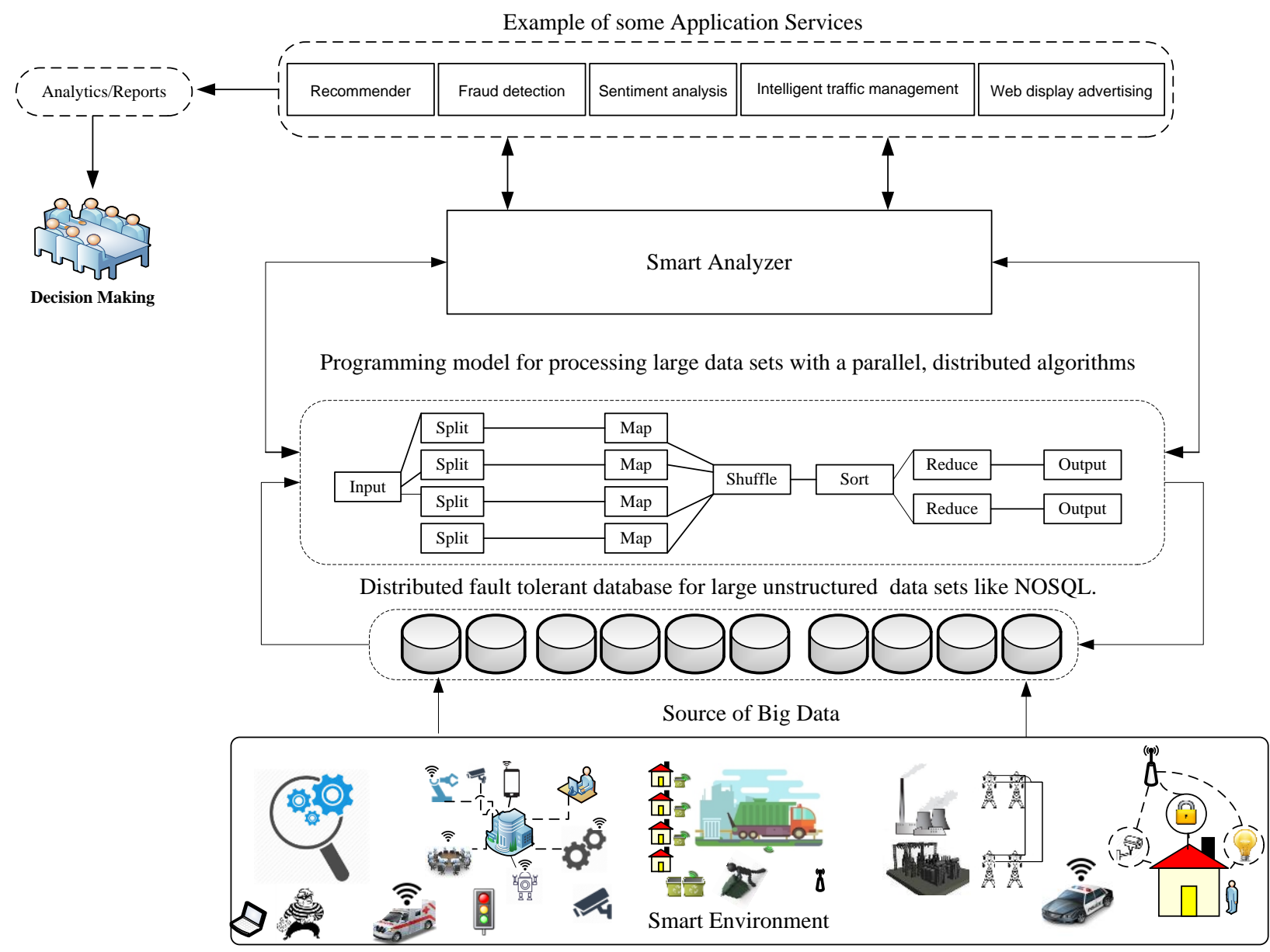

Fig.2 Construction frame of big data technologies for smart city

\subsection{Future Business Model}

Smart city and big data serve as the key components for reforming the future business models. According to (Osterwalder et al., 2005), "a business model is a conceptual tool that contains a set of elements and their relationships and allows expressing the business logic of a specific firm. It is a description of the value a company offers to one or several segments of customers and of the architecture of the firm and its network of partners for creating." The big data collected from a smart environment can play an important role in accelerating the process of business model. Uncovering hidden patterns, correlations, and other insights from large amounts of smart environment data can enable business owners to improve their businesses and serve their customers. The analytics of 
data collected from the smart environment can assist in acquiring knowledge to predict market trends. Various product recommendations can be provided after analyzing seasonal variations. For promotion purposes, analytics can help in strategically placing an advertisement, thereby enabling people to make a valuable decision in terms of understanding customers and products, and can help in identifying the potential risks and opportunities for a company. Moreover, analytics can help enterprises make smart strategies after analyzing employee data. Analyzing the products that people search for and buy can help business owners increase their income by fulfilling the demands of the customers based on their needs. After analyzing the complaints datasets of customers, companies can analyze the products that lead toward revenue loss. After analyzing the big data, hypotheses can be proposed that can later be experimentally verified.

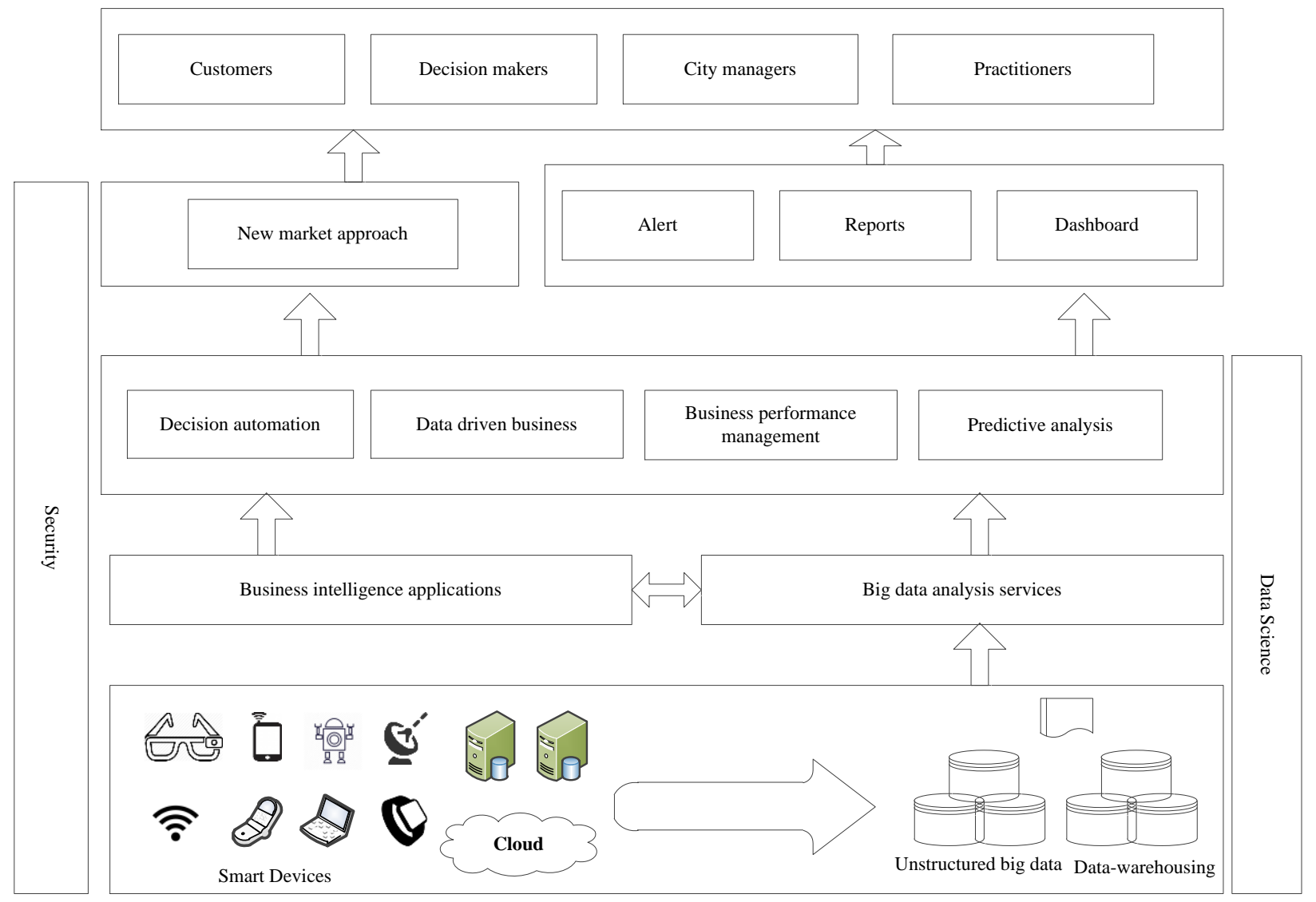

Fig.3 Business model for big data and smart city

As shown in Figure 3, data from multiple sources are stored in a database. Such data can be used by the business intelligence and big data analytics model to predict future behavior with increasing precision, decision automation, data driven business, and performance management. The outcomes of the analysis can be shown in a form of report or alert. The dashboard is used for easy interaction with the models. The source of data, business intelligence, and analytics as well as the application layer represent the data science, which offer a set of processes and play a role in extracting insights from the unstructured big data. The ideal future business model requires a security model 
throughout the processes and examines security issues from a systems perspective to provide business value to an organization.

\subsection{Case Studies of Smart City}

In this section, we provide certain case studies that have shown how the smart city and IoT technologies are applied as well as the amount of the data generated using such applications and technologies.

\subsection{City of Stockholm}

Stockholm has recently implemented smart management and smart applications to address its traffic and environmental issues. Many waste-collecting vehicles were deployed throughout the city to manage waste. However, the city faced challenges associated with waste transport and inner city traffic. Thus, half a million entries of waste fractions, weights, and locations were realized. Such a large amount of data was used to collect and analyze waste management collection data to identify the inefficiencies in waste collection routes within the city. A shared waste management vehicle fleet was recommended as a particularly good policy intervention (Shahrokni et al., 2014).

\subsection{City of Helsinki}

The development of Helsinki as a smart city was inspired by the existence of open public data. Such data can be accessed by individuals, the academic sector, government, businesses, and research institutions. In 2013, more than 1,030 databases were made available that cover a wide range of urban phenomena, such as transport, economics, conditions, employment, and well-being. The Helsinki Region Infoshare Project is one of the pioneering open urban data platforms. The platform has recently been awarded with the European Prize for Innovation in Public Administration in the category of empowering citizens. The jury report suggests that the opening up of decisionmaking information via an electronic case management system provides citizens with a great opportunity to be significantly involved in public decision making (Caragliu et al., 2011; Catriona Manville et al., 2014).

\subsection{City of Copenhagen}

Many projects related to smart city solutions are analyzed for Copenhagen from two aspects, the success factors and economics. Copenhagen has been ranked eighth by Boyd Cohen in a list of smart European cities. Copenhagen aims to become the world's first carbon-neutral capital by 2025 . Therefore, the city is currently implementing a range of new and innovative solutions within the fields of transport, waste, water, heating, and alternative energy sources to support this aim and to improve its sustainability through a large number of initiatives. Copenhagen has an extensive network of cycle lanes, which are still being expanded. The cycling solution is embedded in a broad concept of improving traffic in the city, for example, easy switching from bicycles to public transport and the provision of sufficient parking spaces for bicycles. This circumstance generates useful information on improvements in the cycling infrastructure and helps identify other areas for improvement (Catriona Manville et al., 2014). 


\subsection{Research Challenges}

The age of big data in the smart city (Lohr, 2012) has opened a vast number of opportunities for new value creation. Moving forward, such progress comes with many challenges, most of which are multi-dimensional and can be addressed from different multidisciplinary perspectives. In this section, some of the key research challenges related to business and technology are presented. Our discussions of the challenges are divided in two parts. In first part, we address the challenges from the business perspective. In the second part, we address the challenges from the technological perspective.

\subsection{Business Challenges}

In recent years, the smart city business model has gained attention from commercial companies through the realization of a growing market for the future development of smart city technologies, and the supply of big data has increased (Kitchin, 2014). However, business leaders face the challenges of using the IoT and big data to improve their businesses. In this subsection, we highlight certain challenges related to business, which require the attention of the business owners to fully realize the benefit of big data for the smart city.

\subsubsection{Planning}

Building an integrated master planning and control methodologies of big data for the smart city is the main challenge encountered by smart city planners. Much of the information that must be addressed will require time and money to cost effectively meet the potential future requirements. Designing a model of good practice and guidelines will help the authorities understand further the planning for smart city aspirations at minimal cost (bsi, 2016). Anthopoulos and Vakali (2012) emphasized and measured smart city and urban planning interrelation and identified the meeting points among them. The authors indicated that planning dimensions can be affected by smart city's stakeholders via participatory policy making, whereas the smart city infrastructure must be recognized and capitalized.

\subsubsection{Sustainability}

Real-time interaction and communication with IoT technologies, big data applications, and the huge amount of stakeholder's information can be used resiliently and sustainably, thereby allowing them to reach their full potential (Kyriazis et al., 2013). A sustainable smart city can use the power of IoT and big data to improve its services. The challenge in urban cities is to recognize the benefits of using big data to improve the quality of life for its citizens through improved decision making as well as enhanced information and customer services (Engineering, 2015). The researchers in (Vilajosana et al., 2013) pointed out that the complexity of smart city development can be attributed to the scarcity of resources to trigger infrastructural investments as well as the scaling up of the model and making it self-sustainable.

\subsubsection{Source of Markets and Customer}


New technologies can extend the reach of organizations, improve management decisions, and accelerate the development of new products and services (Bughin et al., 2010). However, the large diversity of devices and smart applications used in an urban city introduces difficulties for businesses to find the right sources of market and customers. For example, many social media applications can be used by customers daily; tracking such customers may require extra effort by the organizations to identify the right customers. Moreover, IoT has brought new challenges in terms addressing various sensors and objects.

\subsubsection{Cost of Acquiring Smart City}

Another challenge for smart city adoption is cost. Given that a smart city needs the integration of different components, acquiring them may be costly for the government because of the scarcity in natural and human resources (Hollands, 2015). Thus, open standard frameworks and technologies will provide cost reduction in this area (Ortiz-Rangel et al., 2015). However, efforts on open standard frameworks and technologies must be intensified. Robust open standards, which are maintained through collaboration and consensus, will facilitate interoperability and data exchange among different devices, applications, products, or services in the smart city.

\subsubsection{Cloud computing integration}

Although cloud computing technologies promise flexibility and low costs to host big data, the integration of these technologies with IoT to realize the benefits of a smart city is a major challenge. Despite cloud computing services recently witnessing huge improvements, their adoption for smart city integration poses several issues in security, management, and open platforms (Soto et al., 2016). These issues arise because of the need to move certain data and processes out of the firewall into the cloud. A suitable cloud business framework to address issues around cloud integration (Chang, 2015a), security, management, and platform flexibility for smart city applications must be developed. Moreover, the ability to customize services based on customer recommendation or needs attracts numerous customers to such telecommunications providers, thereby generating increased revenue. Furthermore, cloud providers make money through data center colocation by hosting their systems in multiple vendor facilities, granting them ease in offering services in different or diverse geographical settings (Wood et al., 2009).

\subsection{Technological Challenges}

The growing demand for smart city and big data stimulates innovation, and the development of new smart applications is becoming important. However, to improve the services of the smart city, the collected data must be managed well. This subsection aims to address some of the technological challenges related to big data and smart city.

\subsubsection{Privacy}

In the era of big data, information on individuals in the smart city is exposed to analysis, sharing, and misuse, which is a condition that gives rise to concerns about profiling, stealing, and loss of control (Tene \& Polonetsky, 2012). For instance, many personally identifying data regarding citizens, such as social activities and locations, are collected 
every day. Although many efforts have been made to address such concern, securing the vast amount of private data collected by smart city technologies from hackers and theft is becoming a challenging problem. Moreover, although successful cyberattacks on cities remain relatively rare, smart city technologies raise a number of cyber-security concerns that require attention. The researchers in (Bello-Orgaz et al., 2016; Chang et al., 2016) identified privacy issues that may require further research in the future, such as data communication, graph matching, awareness, and evaluation of privacy preserving services. Data should be kept private; however, if data are lost or hacked, then effective services can prevent the next wave of hacking and restore service (Chang, 2015b).

\subsubsection{Data Analytics}

In any urban city, data analysis is considered the main source of promoting growth and wellbeing. This data come with processing challenges that must be addressed to increase citizens' quality of life and make their cities sustainable (Vincenzo Gulisano et al., 2016). In a smart city, the data are gathered from various objects; gaining insights from the data and making decisions require novel algorithms and visualization techniques, which affect smart city-focused activities (STAFF, 2015). For instance, energy or water losses caused by faulty devices can be reduced by matching the consumption measured by users' meters with that measured by other utilities' systems (Vincenzo Gulisano et al., 2016). Thus, on-the-fly processing of data becomes increasingly important, whereas traditional store-then-process approaches, in which each company retrieves its data and stores it for access it in the future, may no longer be appropriate.

\subsubsection{Data Integration}

Smart city data encompass various data formats using a wide variety of intelligent objects embedded throughout the city. However, the vision of the smart city is to integrate such a large amount of data from multiple sources; data integration within the smart city is one of the important challenges to be addressed ( $\mathrm{Su}, \mathrm{Li}, \& \mathrm{Fu}, 2011)$. In recent years, several technologies have been integrated into smart cities, which reduce the technical barriers of addressing the data. Nevertheless, data quality is one of the challenging problems in any data integration mechanism, especially if the data are incorrect, missing, use the wrong format, and/or are incomplete (Gouveia et al., 2016).

\subsubsection{GIS-based Visualization}

Geographic information systems (GIS) are widely used for mapping and analyzing spatial data; GIS has recently gained popularity in urban planning, environmental planning, traffic monitoring, and transportation mode detection (Jin et al., 2014). Efficient GIS-based visualization is critical to smart city application because it can provide interactive and easy-to-use platforms for the users. These platforms, however, call for the integration of 3D and touch screen technologies with smart city applications. Such integration can enable policy makers to convert data into knowledge, which is critical in fast decision making (Gubbi et al., 2013). The information extracted from the modeled data will be represented based on the user's need. Creating efficient and flexible devices and software applications based on modern technologies for the smart city is indeed an interesting area toward realizing the vision of smart environment. 


\subsubsection{QoS}

To establish a smart city, a number of technologies must be integrated. The QoS provided by different technologies is another challenge for smart city adoption (Bellavista et al., 2015). For instance, reliable, flexible, scalable, and fault-tolerant networks must not be compromised to achieve the objective of a smart city. Similarly, highly scalable data storage and processing platforms that are supported by efficient cloud-based services selection are an open challenge. The QoS provided by these technologies must be satisfactory before smart city application is fully integrated. The frameworks and methodologies for determining and applying QoS parameters in a smart city are important (Jalali et al., 2015).

\subsubsection{Computational Intelligence Algorithms for Smart City Big Data Analytics}

Computational intelligence algorithms, such as neural network, genetic algorithm, artificial bee colony and particle swarm optimization, cuckoo search algorithm, flower pollination algorithm, chicken swarm optimization, and bat algorithm, are effective, efficient, and robust in knowledge engineering, which comprises soft computing, machine learning, and data mining (Jin et al., 2014; Tsihrintzis et al., 2016). However, the effectiveness, efficiency, and robustness of computational intelligence algorithms are limited to small data sets (Tsai et al., 2014). As such, these algorithms are inapplicable in smart city big data analytics. The big data generated from the smart city has rendered the existing computational intelligence algorithms irrelevant in big data analytics. When the capacity of the data set increases, the effectiveness, efficiency, and robustness of the computational intelligence algorithms normally diminish, thereby making them inappropriate for exploring knowledge in big data generated from the smart city (Singh et al., 2014).

\subsection{Conclusions}

The significant increase in connected devices in urban cities has led to the rapid growth of data, which has elicited the attention of many researchers in different research domains. This paper aims to offer a comprehensive view of the role of big data in a smart city. In this context, we discussed the enabling technologies used in the smart city. The future business model and architecture with the aim of managing big data for smart city were also proposed, and the applications of the smart cities in which big data analytics can play an important role were discussed. Different case studies were also examined. Finally, several open research challenges were explained to provide the research directions to the new researchers in the domain. Big data can play an important role in terms of gaining valuable information and for decision-making purposes. However, big data research in a smart city is in its infancy and the discussed challenges that remain to be addressed make it a practical field.

\section{Acknowledgment}

This work is fully funded by Malaysian Ministry of Higher Education under the University of Malaya High Impact Research Grant UM.C/625/1/HIR/MOE/FCSIT/03 and RP012C-13AFR. 


\section{Reference}

Abdalla, I., \& Venkatesan, S. (2012). Remote Subscription Management of M2M Terminals in 4G Cellular Wireless Networks. Proceedings of the 37th Annual Ieee Conference on Local Computer Networks (Lcn 2012), 869877.

Adeli, H., \& Jiang, X. (2009). Intelligent infrastructure: neural networks, wavelets, and chaos theory for intelligent transportation systems and smart structures: Crc Press.

Ahmad, M. (2015). 4G and 5G wireless: How they are alike and how they differ. from http://www.androidauthority.com/4g-and-5g-wireless-how-they-are-alike-and-how-they-differ-615709/

Al Nuaimi, E., Al Neyadi, H., Mohamed, N., \& Al-Jaroodi, J. (2015). Applications of big data to smart cities. Journal of Internet Services and Applications, 6(1), 1-15.

Anthopoulos, L. G., \& Vakali, A. (2012). Urban planning and smart cities: Interrelations and reciprocities The Future Internet (pp. 178-189): Springer.

Armbrust, M., Fox, A., Griffith, R., Joseph, A. D., Katz, R., Konwinski, A., . . Stoica, I. (2010). A view of cloud computing. Communications of the ACM, 53(4), 50-58.

Atzori, L., Iera, A., \& Morabito, G. (2010). The internet of things: A survey. Computer networks, 54(15), 27872805.

Batty, M. (2013). Big data, smart cities and city planning. Dialogues in Human Geography, 3(3), $274-279$.

Bellavista, P., Corradi, A., \& Reale, A. (2015). Quality-of-Service in Data Center Stream Processing for Smart City Applications Handbook on Data Centers (pp. 1047-1076): Springer.

Bello-Orgaz, G., Jung, J. J., \& Camacho, D. (2016). Social big data: Recent achievements and new challenges. Information Fusion, 28, 45-59.

Borgia, E. (2014). The Internet of Things vision: Key features, applications and open issues. Computer Communications, 54, 1-31.

bsi. (2016). PD 8101 Smart city planning guidelines. Retrieved 25 April 2016, 2016, from http://www.bsigroup.com/en-GB/smart-cities/Smart-Cities-Standards-and-Publication/PD-8101-smartcities-planning-guidelines/

Bughin, J., Chui, M., \& Manyika, J. (2010). Clouds, big data, and smart assets: Ten tech-enabled business trends to watch. McKinsey Quarterly, 56(1), 75-86.

Caragliu, A., Del Bo, C., \& Nijkamp, P. (2011). Smart cities in Europe. Journal of urban technology, 18(2), 65-82.

Catriona Manville, Gavin Cochrane, Jonathan Cave, Jeremy Millard, Jimmy Kevin Pederson, Rasmus Kåre Thaarup, . . . Bas Kotterink. (2014). Mapping smart cities in the EU. Retrieved 4/11/2016, 2016, from http://www.smartcities.at/assets/Publikationen/Weitere-Publikationen-zum-Thema/mappingsmartcities.pdf

Chang, V. (2015a). A proposed cloud computing business framework: Nova Science Publisher.

Chang, V. (2015b). Towards a Big Data system disaster recovery in a Private Cloud. Ad Hoc Networks, 35, 65-82. doi: http://dx.doi.org/10.1016/j.adhoc.2015.07.012

Chang, V., Bacigalupo, D., Wills, G., \& Roure, D. D. (2010). A Categorisation of Cloud Computing Business Models. Paper presented at the Proceedings of the 2010 10th IEEE/ACM International Conference on Cluster, Cloud and Grid Computing.

Chang, V., Ramachandran, M., Yao, Y., Kuo, Y.-H., \& Li, C.-S. (2016). A resiliency framework for an enterprise cloud. International Journal of Information Management, 36(1), 155-166.

Chang, V., Walters, R. J., \& Wills, G. (2013). The development that leads to the Cloud Computing Business Framework. International Journal of Information Management, 33(3), 524-538. doi: http://dx.doi.org/10.1016/j.ijinfomgt.2013.01.005

Chang, V., Wills, G., \& Roure, D. D. (2010, 5-10 July 2010). A Review of Cloud Business Models and Sustainability. Paper presented at the 2010 IEEE 3rd International Conference on Cloud Computing.

Chen, M., Mao, S., \& Liu, Y. (2014). Big data: A survey. Mobile Networks and Applications, 19(2), $171-209$.

Chen, S.-y., Song, S.-f., Li, L., \& Shen, J. (2009). Survey on smart grid technology. Power System Technology, 33(8), 1-7.

Chourabi, H., Nam, T., Walker, S., Gil-Garcia, J. R., Mellouli, S., Nahon, K., . . . Scholl, H. J. (2012). Understanding smart cities: An integrative framework. Paper presented at the System Science (HICSS), 2012 45th Hawaii International Conference on.

Dargie, W. W., \& Poellabauer, C. (2010). Fundamentals of wireless sensor networks: theory and practice: John Wiley \& Sons. 
Dean, J., \& Ghemawat, S. (2008). MapReduce: simplified data processing on large clusters. Communications of the ACM, 51(1), 107-113.

Demirkan, H. (2013). A smart healthcare systems framework. It Professional, 15(5), 38-45.

Dobre, C., \& Xhafa, F. (2014). Intelligent services for big data science. Future Generation Computer Systems, 37, 267-281.

Engineering, S. o. C. M. a. (2015). Smart and Sustainable': Using Big Data to Improve Peoples' Lives in Cities. Retrieved 26 April 2016, 2016, from https://www.reading.ac.uk/CME/NewsItems/cme-newsSmartandSustainableUsingBigDatatoImprovePeoplesLivesinCities.aspx

Fan, W., \& Bifet, A. (2013). Mining big data: current status, and forecast to the future. ACM SIGKDD Explorations Newsletter, 14(2), 1-5.

George, L. (2011). HBase: the definitive guide: " O'Reilly Media, Inc.".

Gouveia, J. P., Seixas, J., \& Giannakidis, G. (2016). Smart City Energy Planning: Integrating Data and Tools. Paper presented at the Proceedings of the 25th International Conference Companion on World Wide Web.

Gubbi, J., Buyya, R., Marusic, S., \& Palaniswami, M. (2013). Internet of Things (IoT): A vision, architectural elements, and future directions. Future Generation Computer Systems, 29(7), 1645-1660.

Hashem, I. A. T., Anuar, N. B., Gani, A., Yaqoob, I., Xia, F., \& Khan, S. U. (2016). MapReduce: Review and open challenges. Scientometrics, 1-34. doi: 10.1007/s11192-016-1945-y

Hashem, I. A. T., Yaqoob, I., Anuar, N. B., Mokhtar, S., Gani, A., \& Khan, S. U. (2015). The rise of "big data" on cloud computing: review and open research issues. Information Systems, 47, 98-115. doi: http://dx.doi.org/10.1016/j.is.2014.07.006

Hawilo, H., Shami, A., Mirahmadi, M., \& Asal, R. (2014). NFV: state of the art, challenges, and implementation in next generation mobile networks (vEPC). Network, IEEE, 28(6), 18-26.

Hollands, R. G. (2015). Critical interventions into the corporate smart city. Cambridge Journal of Regions, Economy and Society, 8(1), 61-77.

Jalali, R., El-Khatib, K., \& McGregor, C. (2015). Smart city architecture for community level services through the internet of things. Paper presented at the Intelligence in Next Generation Networks (ICIN), 2015 18th International Conference on.

Jimenez, C. E., Solanas, A., \& Falcone, F. (2014). E-government interoperability: Linking open and smart government. Computer, 47(10), 22-24.

Jin, J., Gubbi, J., Marusic, S., \& Palaniswami, M. (2014). An information framework for creating a smart city through internet of things. Internet of Things Journal, IEEE, 1(2), 112-121.

Ju, G., Cheng, M., Xiao, M., Xu, J., Pan, K., Wang, X., . . Shi, F. (2013). Smart Transportation Between Three Phases Through a Stimulus-Responsive Functionally Cooperating Device. Advanced Materials, 25(21), 2915-2919.

Kang, Y.-S., Park, I.-H., Rhee, J., \& Lee, Y.-H. (2016). MongoDB-Based Repository Design for IoT-Generated RFID/Sensor Big Data. Ieee Sensors Journal, 16(2), 485-497. doi: 10.1109/jsen.2015.2483499

Khan, N., Yaqoob, I., Hashem, I. A. T., Inayat, Z., Mahmoud Ali, W. K., Alam, M., . . Gani, A. (2014). Big Data: Survey, Technologies, Opportunities, and Challenges. The Scientific World Journal, 2014, 18. doi: $10.1155 / 2014 / 712826$

Kitchin, R. (2014). The real-time city? Big data and smart urbanism. GeoJournal, 79(1), 1-14.

Kyriazis, D., Varvarigou, T., Rossi, A., White, D., \& Cooper, J. (2013). Sustainable smart city IoT applications: Heat and electricity management \& Eco-conscious cruise control for public transportation. Paper presented at the World of Wireless, Mobile and Multimedia Networks (WoWMoM), 2013 IEEE 14th International Symposium and Workshops on a.

Lai, C. S., \& McCulloch, M. D. (2015). Big Data Analytics for Smart Grid. Retrieved 4/23/2016, 2016, from http://smartgrid.ieee.org/newsletters/october-2015/big-data-analytics-for-smart-grid

Lee, J.-S., Su, Y.-W., \& Shen, C.-C. (2007). A comparative study of wireless protocols: Bluetooth, UWB, ZigBee, and Wi-Fi. Paper presented at the Industrial Electronics Society, 2007. IECON 2007. 33rd Annual Conference of the IEEE.

Lohr, S. (2012). The age of big data. New York Times, 11.

Meijer, A., \& Bolívar, M. P. R. (2015). Governing the smart city: a review of the literature on smart urban governance. International Review of Administrative Sciences, 0020852314564308.

Mell, P., \& Grance, T. (2011). The NIST definition of cloud computing.

Morabito, V. (2015). Big Data and Analytics for Government Innovation Big Data and Analytics (pp. 23-45): Springer. 
Neumeyer, L., Robbins, B., Nair, A., \& Kesari, A. (2010, 13-13 Dec. 2010). S4: Distributed Stream Computing Platform. Paper presented at the Data Mining Workshops (ICDMW), 2010 IEEE International Conference on.

Operators Network. (2012). Network Functions Virtualization, An Introduction, Benefits, Enablers, Challenges and Call for Action. Paper presented at the SDN and OpenFlow SDN and OpenFlow World Congress.

Ortiz-Rangel, M., Rueda-Vasquez, L., Duarte-Gualdron, C., Petit, J., \& Ordonez-Plata, G. (2015). Towards a smart city: Design of a domestic smart grid. Paper presented at the Innovative Smart Grid Technologies Latin America (ISGT LATAM), 2015 IEEE PES.

Osterwalder, A., Pigneur, Y., \& Tucci, C. L. (2005). Clarifying business models: Origins, present, and future of the concept. Communications of the association for Information Systems, 16(1), 1.

Oualhaj, O. A., Kobbane, A., Sabir, E., Ben-othman, J., \& Erradi, M. (2015). A ferry-assisted solution for forwarding function in Wireless Sensor Networks. Pervasive and Mobile Computing, 22, 126-135. doi: 10.1016/j.pmcj.2015.05.003

Owen, S., Anil, R., Dunning, T., \& Friedman, E. (2011). Mahout in action: Manning.

Patil, M., \& Biradar, R. C. (2012). A survey on routing protocols in Wireless Sensor Networks. Paper presented at the Networks (ICON), 2012 18th IEEE International Conference on.

Roy, N., Pallapa, G., \& Das, S. K. (2007). A middleware framework for ambiguous context mediation in smart healthcare application. Paper presented at the Wireless and Mobile Computing, Networking and Communications, 2007. WiMOB 2007. Third IEEE International Conference on.

Shahrokni, H., Van der Heijde, B., Lazarevic, D., \& Brandt, N. (2014). Big data GIS analytics towards efficient waste management in Stockholm. Paper presented at the Proceedings of the 2014 conference ICT for Sustainability.

Singh, D., Tripathi, G., \& Jara, A. J. (2014). A survey of internet-of-things: future vision, architecture, challenges and services. Paper presented at the Internet of Things (WF-IoT), 2014 IEEE World Forum on.

Soto, J. A. C., Werner-Kytölä, O., Jahn, M., Pullmann, J., Bonino, D., Pastrone, C., \& Spirito, M. (2016). Towards a Federation of Smart City Services.

STAFF, E. (2015). Big data analysis for Smart Cities. Retrieved 17 April 2016, 2016, from http://blog.eai.eu/bigdata-analysis-for-smart-cities/

$\mathrm{Su}, \mathrm{K} ., \mathrm{Li}, \mathrm{J} .$, \& Fu, H. (2011). Smart city and the applications. Paper presented at the Electronics, Communications and Control (ICECC), 2011 International Conference on.

$\mathrm{Su}, \mathrm{K} ., \mathrm{Li}, \mathrm{J} ., \mathrm{Fu}, \mathrm{H}$. , \& Ieee. (2011). Smart City and the Applications. 2011 International Conference on Electronics, Communications and Control (Icecc), 1028-1031.

Tene, O., \& Polonetsky, J. (2012). Privacy in the age of big data: a time for big decisions. Stanford Law Review Online, 64, 63.

Tsai, C.-W., Lai, C.-F., \& Vasilakos, A. V. (2014). Future Internet of Things: open issues and challenges. Wireless Networks, 20(8), 2201-2217.

Tsihrintzis, G. A., Virvou, M., \& Jain, L. C. (2016). Intelligent Computing Systems: Emerging Application Areas (Vol. 627): Springer.

Vilajosana, I., Llosa, J., Martinez, B., Domingo-Prieto, M., Angles, A., \& Vilajosana, X. (2013). Bootstrapping smart cities through a self-sustainable model based on big data flows. Communications Magazine, IEEE, 51(6), 128-134.

Vincenzo Gulisano, Magnus Almgren, \& Papatriantafilou, M. (2016). When Smart Cities meet Big Data. Retrieved 2016, from http://ercim-news.ercim.eu/en98/special/when-smart-cities-meet-big-data

Willke, H. (2007). Smart governance: governing the global knowledge society: Campus Verlag.

Wood, T., Tarasuk-Levin, G., Shenoy, P., Desnoyers, P., Cecchet, E., \& Corner, M. D. (2009). Memory buddies: exploiting page sharing for smart colocation in virtualized data centers. Paper presented at the Proceedings of the 2009 ACM SIGPLAN/SIGOPS international conference on Virtual execution environments. 